\title{
Effect of Different Current Densities in the Studies of 1/f noise on the Thin Films of Silver
}

\author{
S.Victor Vedanayakam ${ }^{1}$, D. Punyaseshudu ${ }^{2}$ \\ 1 Asst. Professor, Dept. of Physics, MITS, Madanapalle, A.P. India \\ 2 Professor, Dept. of Physics, Rayalaseema University, Kurnool, A.P. India
}

\begin{abstract}
Silver (Ag) thin films are having remarkable characteristics. They have found extensive applications especially in electronic and optical devices. Silver thin films have potential applications in ultra-high density optical non-volatile memories, transparent electrodes and in fluorescence imaging. Measurements of nonlinear properties are very interesting from the point of the view of optoelectronic and all optical switches. Hencel/f noise and nonlinear effects in Silver thin films for different current densities on varying the thickness of the films, at room temperature are studied in the present work. The specific dependence of $1 / f$ noise on the thickness of the film, the effect of current densities on $1 /$ f noise for the films of various thicknesses $\left(430 A^{\circ}\right.$ to $\left.1180 A^{\circ}\right)$ has been investigated. It is noticed that, for a constant current, the thickness of the film leads to an increase of $1 / f$ noise. If noise plays an important role in choosing frequency band in which a device can be effectively used. Silver thin films are regarded as a material with many attracting properties such as good conduction, high transmission coefficient etc.
\end{abstract}

Key Words: 1/f noise, Ag film, FFT, Current densities, frequency band, $\gamma$ value, etc.

\section{Introduction}

Silver thin films are regarded as a material with many attracting properties such as good conduction, high transmission coefficient in visible spectral domain etc. It is specially used in optoelectronic devices. Using the newly developed measuring system the studies are undertaken and found that the results are matching the theoretical values.

Recently, there has been sharply increasing interest in 1/f noise in thin metal films and other physical systems, which can be accounted for their wide application in different areas of physics and technology, especially in modern micro-electronics which makes high demands of thin films of different materials in manufacturing commutation layers, resistors, and contacts for integrated microcircuits.

$1 / \mathrm{f}$ noise plays an important role in choosing frequency band in which a device can be effectively used. As $1 / \mathrm{f}$ noise comes from the fluctuations of microscopic entities, it can act as a probe of what is happening physically at the microscopic scale. Characterization of noise with a $1 / \mathrm{f}$ like spectrum, and referred to as an excess or flicker noise, provided most important problems in modern radio physics. This noise limits the sensitivity and stability or many radio electronic devices, the requirements to which are enhancing constantly. These fluctuations reflect many processes at the electron and atom levels and specific features of solid state micro-structure which makes $1 / \mathrm{f}$ noise a valuable informative parameter for evaluating the quality of materials and reliability of devices containing semiconductors and integrated micro chips. It is also used to predict the electro migration immunity of thin film metallization in integrated micro chips.

Characterization of noise with a 1/f - like spectrum, also referred to as an excess or flicker noise, provided one of the most important problems in modern radio physics. The reason is that, on the one hand, the nature of these fluctuations remains poorly knew although their possible origin has been discussed in scientific literature for many decades. On the other hand, this noise limits the sensitivity and stability of many radio electronic devices, the requirements of which are enhancing constantly.

\section{Properties of $\mathbf{1} / \mathbf{f}$ noise}

The main aspects of the $1 / \mathrm{f}$ noise are (the discussion is centered on device noise and can be extended to any other phenomena) as follows.

Amplitude Distribution: The amplitude distribution of 1/f noise is strongly Gaussian. Although considerable deviations from Gaussian distributions have been observed, they are attributed to interference effects with additional low frequency noise components particularly burst noise.

Stationary: A process is said to be statistically stationary when the statistical properties are independent of the epoch in which they are measured. In the $1 / \mathrm{f}$ noise literature one comes across statements to the effect that $1 / \mathrm{f}$ noise is a stationary fluctuation as well as those saying that it exhibits some degree of non-stationary. In 
order to clarify the situation, two kinds of noises namely the band limited 1/f noise and low pass filtered 1/f noise have to be studied. The band limited $1 / \mathrm{f}$ noise is that for which the power spectral density is defined only for any frequency between the upper and lower angular frequencies of the pass band considered.

Power Spectral Density: The shape of the power spectral density is of the $\mathrm{f}^{-1}$ type with lying between 0.8 And 1.4. This spectral shape has been observed over a wide range of frequencies form $10^{8} \mathrm{~Hz}$ to $10^{6} \mathrm{~Hz}$ or higher Current Dependence: In homogenous conducting materials, it has been verified that there is a current squared $\left(\mathrm{I}^{2}\right)$ dependence of noise, which led to the belief that $1 / \mathrm{f}$ noise originates from fluctuations in conductivity. However, in junction devices such as diodes and transistors, the current spectral density is observed to be proportional to $\mathrm{I}^{\gamma}$ with $\gamma$ between 1 and 2 .

Silver (Ag) thin films are regarded as a material with many attracting properties such as large energy band gap, good conducting film and high transmission coefficient in visible spectral domain. In recent years, researchers have focused on Ag due to its applications, especially in the field of optoelectronic devices such as solar cells, Phototransistors and diodes, transparent electrodes, gas sensors, etc. These applications of $\mathrm{Ag}$ are based on its specific optical and electrical properties. For example, Ag films show a high ohmic conductivity. In this paper the results of investigations are made on $\mathrm{Ag}$ films. The 1/f noise characterization on film thickness, variation of the current densities is made on $\mathrm{Ag}$ thin films of thickness $430 \mathrm{~A}^{0}, 670 \mathrm{~A}^{0}, 880 \mathrm{~A}^{0}$ and $1180 \mathrm{~A}^{0}$.

\section{1/f Noise and non-linear studies in Ag Thin Films}

Each device under selected biased condition has its own record in the form of digital data file (which is not provided). When plotted directly they look alike, the differences in magnitudes can be noticed but quantitative measurements can't be made. The spectral power density records are obtained using the digital data records as inputs to the MATLAB programs. These FFT records have the unique signatures of noise produced by the device under test, abbreviated as DUT. These observations are of prime significance, containing crucial information regarding the electrical behavior associated with DUT if analyzed using MATLAB programs.

The raw noise records for different components under the present study are shown in the following figures. These plots represent the noise recorded for one individual device. On observation, the noise recordings look alike on first perusal. Nothing seems to be differentiated between any two plots except the noise magnitudes are different.

The noise patterns similar to shown in Fig.1 represent 8-bit pulse code amplitude for Ag film of thickness $430 \mathrm{~A}^{0}$. The observation is of prime significance, containing crucial information regarding the electrical behavior associated with DUT if analyzed using the software. The simplest way of translating the noise data into spectral power density form is known as FFT transform of the noise input. The noise patterns shown in Fig. 2 represent the variation of magnitude of FFT with the frequency for different current densities.

All graphs are plotted in the standard format of $\log \mathrm{f}$ verses $\log$ (spectral power density), after passing the data through the elliptical filter. The elliptical filters are found to be quite suitable for measurements that are recorded randomly. Notch filters were also used in the software to eliminate the stray ac interference.

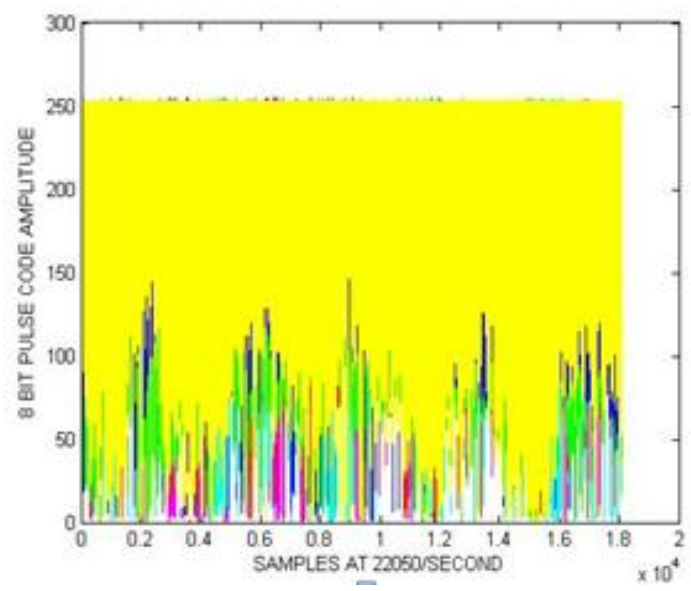

Fig. 1. 8-Bit Pulse Amplitude of Ag Film of thickness $430 \mathrm{~A}^{\circ}$

for Different current densities

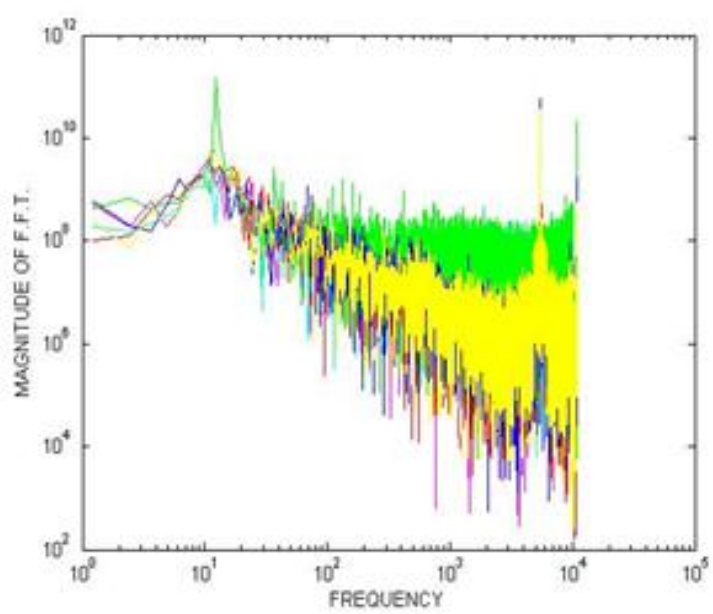

Fig. 2 FFT Amplitude of Ag Film of thickness $430 \mathrm{~A}^{\circ}$

for Different current densities 
These graphs convey better information when they are compared for different films of for different conditions for the same DUT. Plotting them on the same graphical presentation compares two or more plots. This is equivalent to superimposing multiple graphs presented on similar scales. To visualize the difference, the graphs are plotted using different colors. A legend to each graph is added for easy explanation. In the present work $1 / \mathrm{f}$ noise dependence on different conditions is studied. The 1/f noise plots are carefully compared to achieve the objectivity of $1 / \mathrm{f}$ noise studies.

Fig.3.1 is a plot for Silver film of thickness $430 \mathrm{~A}^{0}$ for five current densities. The theoretical estimates predict $\gamma=-1$, while the observed values of $-\gamma$ are $0.555,0.552,0.554,0.558$ and 0.550 at current densities $\left(\mathrm{Acm}^{2}\right) 3192,2612,2210,2150$ and 2018 respectively, with an average value of 553.8. According the estimated error of $\pm 2 \%$, the observed values of $\gamma$ are constant for the three current densities. On increasing the current density, the power $\gamma$ tends to increase for devices and thin films.

1/f noise in Silver thin films of $660 \mathrm{~A}^{0}, 880 \mathrm{~A}^{0}$ and $1130 \mathrm{~A}^{0}$ thickness is presented in Fig 3.2, 3.3 and 3.4. The average $\gamma$ values obtained from the study are $-0.525 .6,-0.515$, and -0.560 respectively. The final results are discussed basing on the investigations that are made on number of samples of same thickness under same environment.

\section{Average slopes of various 1/f graphs}

Fig 3.1: 1/f Noise in $430 \mathrm{~A}^{0}$ Silver Film at Different Current Densities $\mathrm{A} / \mathrm{cm}^{2}$

\begin{tabular}{|c|c|c|c|c|}
\hline $\begin{array}{l}\text { Figure } \\
\text { number }\end{array}$ & Description & $\begin{array}{l}\text { Color of } \\
\text { graph }\end{array}$ & $\begin{array}{l}\text { Current } \\
\text { Density }\end{array}$ & $\begin{array}{c}\text { Average } \\
\text { slope } \\
\gamma \\
\end{array}$ \\
\hline \multirow[t]{5}{*}{ Fig 3.1} & \multirow{5}{*}{$\begin{array}{c}430 \mathrm{~A}^{0} \\
\text { Silver film } \\
\text { at } \\
\text { Different } \\
\text { current } \\
\text { densities }\end{array}$} & Magenta & $\begin{array}{c}3192 \\
\mathrm{~A} / \mathrm{cm}^{2}\end{array}$ & -0.555 \\
\hline & & Cyan & $\begin{array}{c}2612 \\
\mathrm{~A} / \mathrm{cm}^{2}\end{array}$ & -0.552 \\
\hline & & Red & $\begin{array}{c}2210 \\
\mathrm{~A} / \mathrm{cm}^{2}\end{array}$ & -0.554 \\
\hline & & Green & $\begin{array}{c}2150 \\
\mathrm{~A} / \mathrm{cm}^{2}\end{array}$ & -0.558 \\
\hline & & Blue & $\begin{array}{c}2018 \\
\mathrm{~A} / \mathrm{cm}^{2}\end{array}$ & -0.550 \\
\hline
\end{tabular}
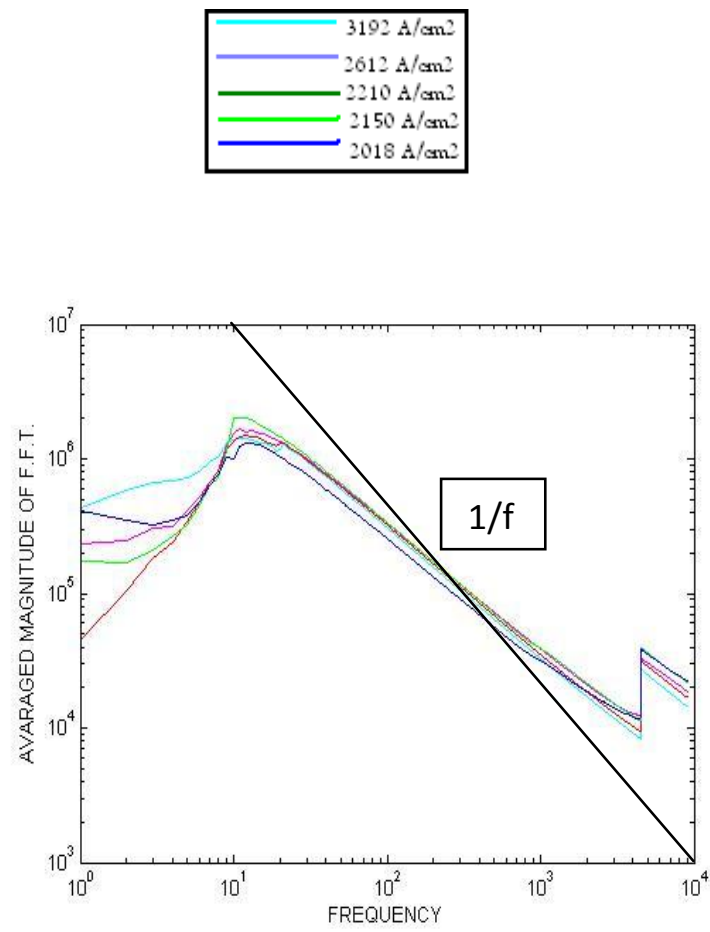
Fig 3.2: $1 / \mathrm{f}$ Noise in $660 \mathrm{~A}^{0}$ Silver Film at Different Current Densities $\mathrm{A} / \mathrm{cm}^{2}$

\begin{tabular}{|c|c|c|c|c|}
\hline $\begin{array}{l}\text { Figure } \\
\text { number }\end{array}$ & Description & $\begin{array}{l}\text { Color of } \\
\text { graph }\end{array}$ & $\begin{array}{l}\text { Current } \\
\text { Density }\end{array}$ & $\begin{array}{c}\text { Average } \\
\text { slope } \\
\gamma\end{array}$ \\
\hline \multirow[t]{5}{*}{ Fig 3.2} & \multirow{5}{*}{$\begin{array}{c}660 \mathrm{~A}^{0} \\
\text { Silver film } \\
\text { at } \\
\text { Different } \\
\text { current } \\
\text { densities }\end{array}$} & Magenta & $\begin{array}{c}2610 \\
\mathrm{~A} / \mathrm{cm}^{2}\end{array}$ & -0.525 \\
\hline & & Cyan & $\begin{array}{c}2325 \\
\mathrm{~A} / \mathrm{cm}^{2}\end{array}$ & -0.523 \\
\hline & & Red & $\begin{array}{c}2280 \\
\mathrm{~A} / \mathrm{cm}^{2}\end{array}$ & -0.530 \\
\hline & & Green & $\begin{array}{c}2115 \\
\mathrm{~A} / \mathrm{cm}^{2}\end{array}$ & -0.528 \\
\hline & & Blue & $\begin{array}{c}1980 \\
\mathrm{~A} / \mathrm{cm}^{2}\end{array}$ & -0.522 \\
\hline
\end{tabular}

\begin{tabular}{|c|c|c|c|c|}
\hline $\begin{array}{l}\text { Figure } \\
\text { Number }\end{array}$ & $\begin{array}{l}\text { Descripti } \\
\text { on }\end{array}$ & $\begin{array}{c}\text { Color of } \\
\text { graph }\end{array}$ & $\begin{array}{l}\text { Current } \\
\text { Density }\end{array}$ & $\begin{array}{c}\text { Average } \\
\text { slope } \\
\gamma\end{array}$ \\
\hline \multirow{5}{*}{ Fig 3.3} & \multirow{5}{*}{$\begin{array}{c}880 \mathrm{~A}^{0} \\
\text { Silver } \\
\text { film at } \\
\text { Different } \\
\text { current } \\
\text { densities }\end{array}$} & Magenta & $\begin{array}{c}2128 \\
\mathrm{~A} / \mathrm{cm}^{2}\end{array}$ & -0.520 \\
\hline & & Cyan & $\begin{array}{c}2015 \\
\mathrm{~A} / \mathrm{cm}^{2}\end{array}$ & -0.515 \\
\hline & & Red & $\begin{array}{c}1984 \\
\mathrm{~A} / \mathrm{cm}^{2}\end{array}$ & -0.510 \\
\hline & & Green & $\begin{array}{c}1741 \\
\mathrm{~A} / \mathrm{cm}^{2}\end{array}$ & -0.522 \\
\hline & & Blue & $\begin{array}{c}1630 \\
\mathrm{~A} / \mathrm{cm}^{2}\end{array}$ & -0.508 \\
\hline
\end{tabular}
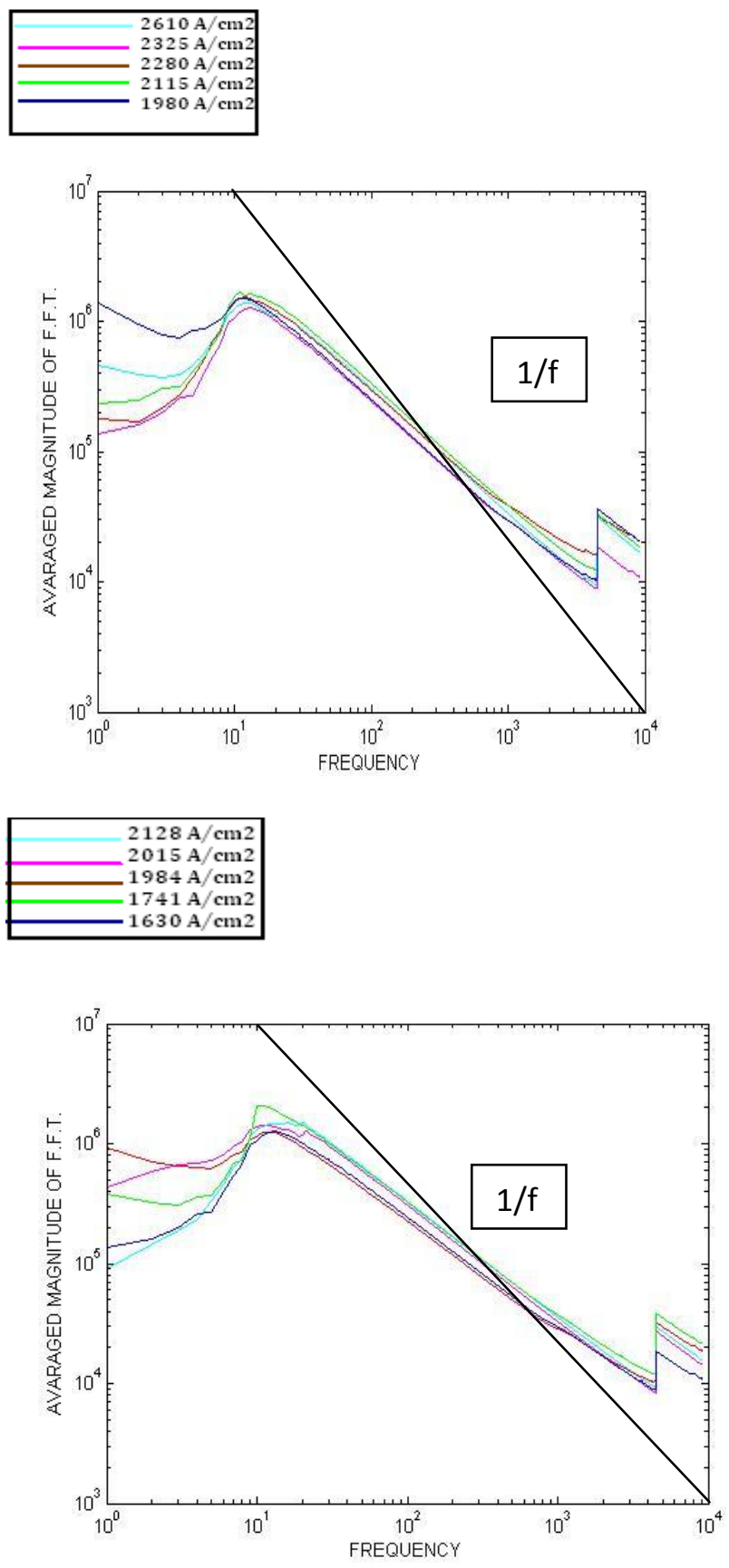

Fig 3.3: 1/f Noise of $\mathbf{8 8 0 A}^{0}$ Silver Film at Different Current Densities A/cm 


\begin{tabular}{|c|c|c|c|c|}
\hline $\begin{array}{l}\text { Figure } \\
\text { number }\end{array}$ & Description & $\begin{array}{c}\text { Color of } \\
\text { graph }\end{array}$ & $\begin{array}{l}\text { Current } \\
\text { Density }\end{array}$ & $\begin{array}{c}\text { Average } \\
\text { slope } \\
\gamma\end{array}$ \\
\hline \multirow[t]{5}{*}{ Fig 3.4} & \multirow{5}{*}{$\begin{array}{c}1180 \mathrm{~A}^{0} \\
\text { Silver film } \\
\text { at } \\
\text { Different } \\
\text { current } \\
\text { densities }\end{array}$} & Magenta & $\begin{array}{c}1596 \\
\mathrm{~A} / \mathrm{cm}^{2}\end{array}$ & -0.560 \\
\hline & & Cyan & $\begin{array}{c}1306 \\
\mathrm{~A} / \mathrm{cm}^{2}\end{array}$ & -0.574 \\
\hline & & Red & $\begin{array}{c}1105 \\
\mathrm{~A} / \mathrm{cm}^{2}\end{array}$ & -0.565 \\
\hline & & Green & $\begin{array}{c}1044 \\
\mathrm{~A} / \mathrm{cm}^{2}\end{array}$ & -0.563 \\
\hline & & Blue & $\begin{array}{c}984 \\
\mathrm{~A} / \mathrm{cm}^{2}\end{array}$ & -0.568 \\
\hline
\end{tabular}

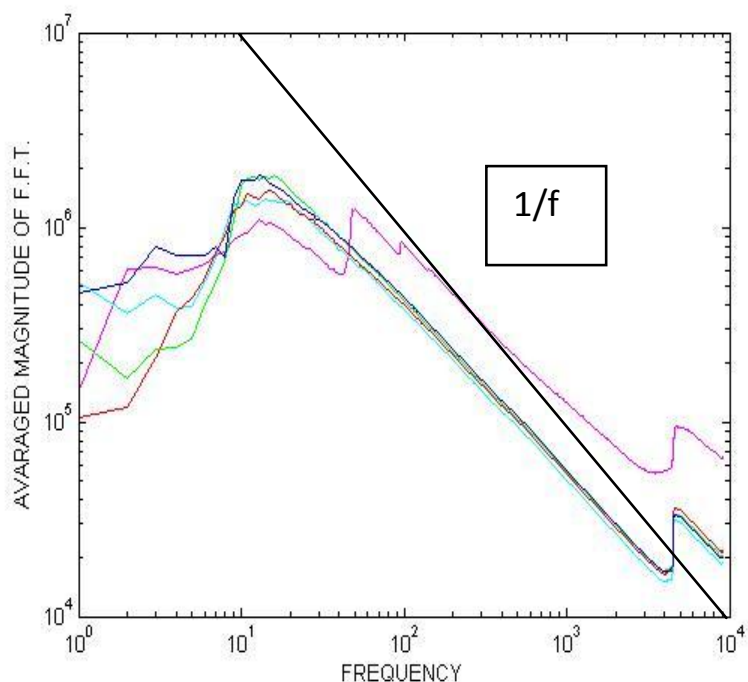

Fig 3.4:1/f Noise of $1180 A^{0}$ Silver Film at Different Current Densities $\mathrm{A} / \mathrm{cm}^{2}$

IV. Average slopes of various 1/f graphs at different currents in Silver films.

\begin{tabular}{|c|c|c|c|c|}
\hline $\begin{array}{l}\text { Figure } \\
\text { number }\end{array}$ & Description & $\begin{array}{c}\text { Color of } \\
\text { graph }\end{array}$ & Thickness & $\begin{array}{c}\text { Average } \\
\text { slope } \\
\gamma\end{array}$ \\
\hline \multirow{4}{*}{ Fig 4.1} & \multirow{4}{*}{ 20mA through Silver films of different thickness. } & Magenta & $1180 \mathrm{~A}^{0}$ & -0.542 \\
\hline & & Cyan & $880 \mathrm{~A}^{0}$ & -0.510 \\
\hline & & Red & $660 \mathrm{~A}^{0}$ & -0.422 \\
\hline & & Green & $430 \mathrm{~A}^{0}$ & -0.527 \\
\hline \multirow{4}{*}{ Fig 4.2} & \multirow{4}{*}{$15 \mathrm{~mA}$ through Silver films of different thickness } & Magenta & $1180 \mathrm{~A}^{0}$ & -0.546 \\
\hline & & Cyan & $880 \mathrm{~A}^{0}$ & -0.512 \\
\hline & & Red & $660 \mathrm{~A}^{0}$ & -0.426 \\
\hline & & Green & $430 \mathrm{~A}^{0}$ & -0.525 \\
\hline \multirow{4}{*}{ Fig 4.3} & \multirow{4}{*}{$10 \mathrm{~mA}$ through Silver films of different thickness } & Magenta & $1180 \mathrm{~A}^{0}$ & -0.551 \\
\hline & & Cyan & $880 \mathrm{~A}^{0}$ & -0.517 \\
\hline & & Red & $660 \mathrm{~A}^{0}$ & -0.420 \\
\hline & & Green & $430 \mathrm{~A}^{0}$ & -0.521 \\
\hline
\end{tabular}


Fig 4.1 1/f Noise of Silver films of different thickness when constant current of $20 \mathrm{~mA}$ is passed through them, under same experimental environment.
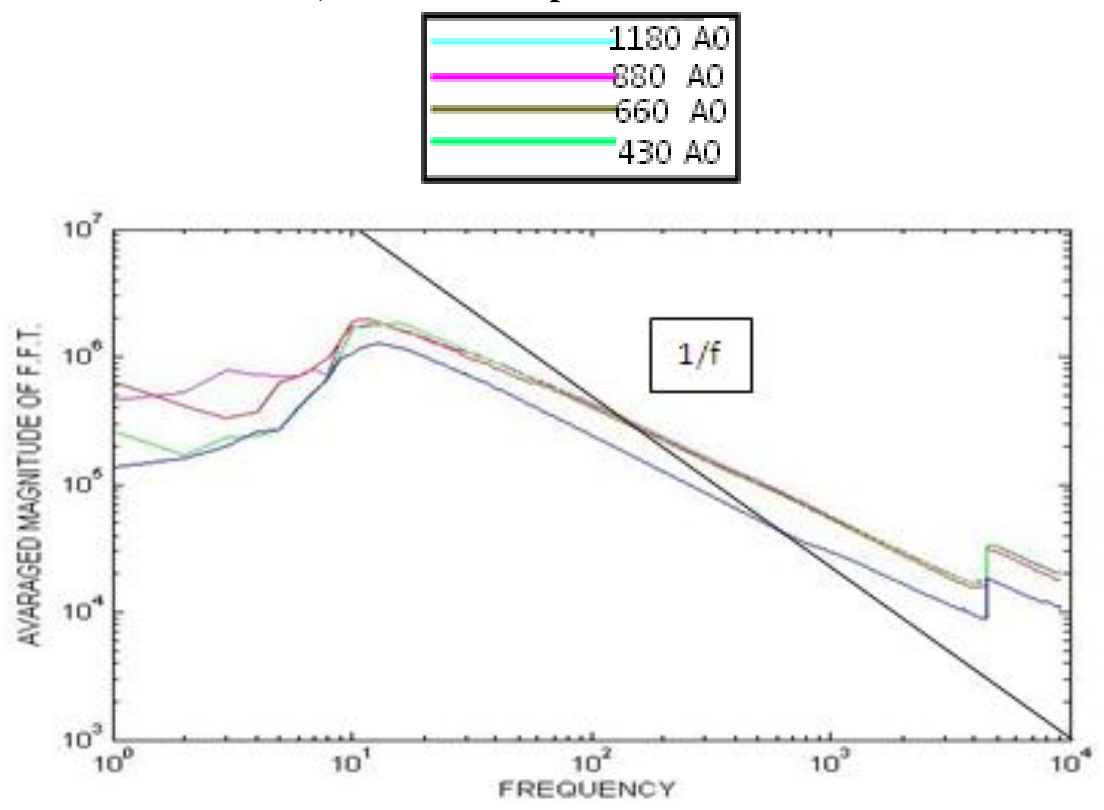

Fig 4.2 1/f Noise of Silver films of different thickness when constant current of $15 \mathrm{~mA}$ is passed through them

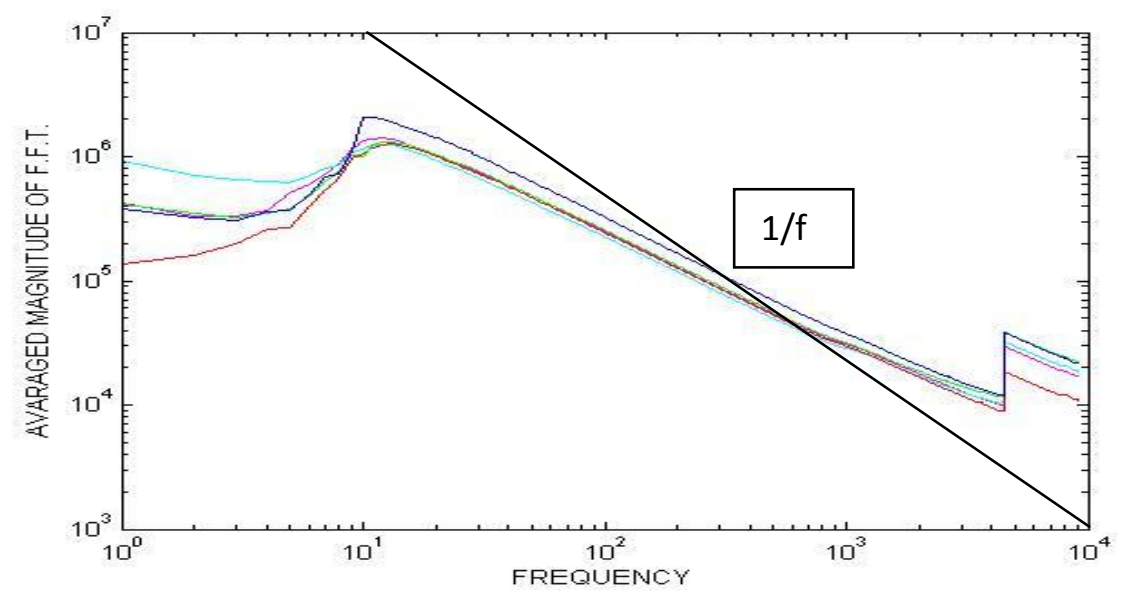

Fig 4.3 1/f Noise of Silver films of different thickness when constant current of $10 \mathrm{~mA}$ is passed through them

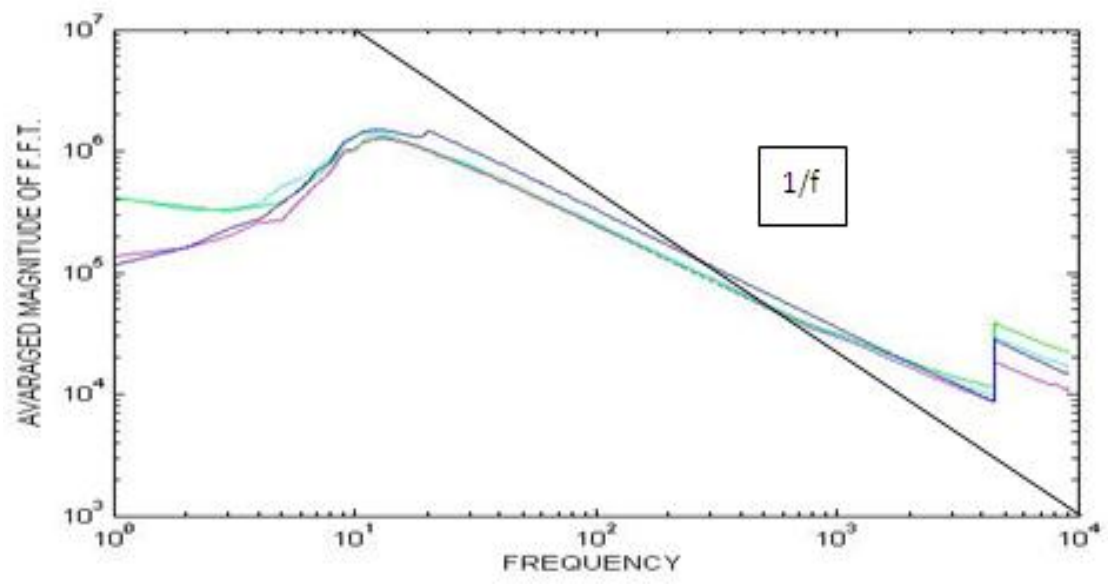




\section{Results And Conclusions:}

The results of present study of $1 / \mathrm{f}$ noise on the thin films of $\mathrm{Ag}$ are very interesting.

1. It is observed that, for a given film, the $\gamma$ values decrease and appear to tend to minus one for diminishing currents or current densities.

2. The average $\gamma$ values obtained from the study of $1 / \mathrm{f}$ noise in Silver thin films of $430 \mathrm{~A}^{0}, 660 \mathrm{~A}^{0}, 880 \mathrm{~A}^{0}$ and $1180 \mathrm{~A}^{0}$ are-553.8, $-0.525 .6,-0.515$, and -0.560 respectively.

3. The average slope i.e the $\gamma$ value in $\mathrm{Ag}$ films of thickness $1180 \mathrm{~A}^{0}$ is -0.560 , represents increase in $1 / \mathrm{f}$ noise for small current densities in this film of higher thicknesses.

4. The average slope i.e the $\gamma$ value in Ag films of thickness $880 \mathrm{~A}^{0}$ is -0.515 , representing decrease in $1 / \mathrm{f}$ noise for small current densities. At this thickness these films may be used for electronic devices.

5. In similar manner $1 / \mathrm{f}$ plots of the four samples at constant currents of $10 \mathrm{~mA}, 20 \mathrm{~mA}$ and $30 \mathrm{~mA}$. The $\gamma$ values are evaluated and plotted, the behavior is almost similar to that presented in the case of current densities except in the case of film of thickness $660 \mathrm{~A}^{0}$.

6. In the case of film of thickness $660 \mathrm{~A}^{0}$ the $\gamma$ value is low for all the currents. It shows that at this thickness $1 / \mathrm{f}$ noise is low for Ag films.

7. It is noticed that for a constant current, increasing the thickness of the film leads to an increase of the $\gamma$ value in $\mathrm{Ag}$ films.

8. In these films the magnitude of noise is increasing while $\gamma$ is decreasing with increasing current density.

\section{References}

[1]. A. Van der Ziel, In: Proc. of the Symposium on 1/f Fluctuations, I. Int. Conf. on 1/f Noise, ed. by T. Musha (Tokyo Institute of Technology Press, Tokyo, Japan, 1977), p 1.

[2]. D.S. Campbell, In: The Use of Thin films in Physical Investigations, ed. by J.C. Anderson (Academic Press, London - New York, 1965), p. 299.

[3]. F.N. Hooge // Physica B+C 114 (1982) 391.

[4]. A. Goswami, Thin Film Fundamentals (New Age International Publisher, New-Delhi, 1966).

[5]. L.I. Maissel, In: Hand Book of Thin Film Technology, ed. by L.I. Maissel, R. Glang (McGraw-Hill, New York, 1970).

[6]. John G. Proakis, Dimitrtis G Manolakis, Digital Signal Processing: Principles, Algorithms, and Application (Prentice Hall, 1995).

[7]. L.A. Udchan, M.S. Jogad, Rao S. Rama // Asian J. Phys. 8 (1999) 207.

[8]. F.N. Hooge, T.G.M. Kleinpenning, L.K.J. Vandamme // Rep. Prog. Phys. 44 (1981) 479

[9]. J.S. Walker, Fast Fourier Transforms, Studies in Advanced Mechanics (CRC Press, 1996).

[10]. F.N.Hooge, IEEE Transactions On Electronic Devices, Vol 41, pp 1926-1935 (1994)

[11]. Proc. $10^{\text {th }}$ Int. Conf. on Noise in Physical Systems and 1/f fluctuations Kyoto, Nov 1991, (Ed. T. Musha, S. Sato, and M. Yamamoto). Tokyo; Ohmsha Ltd.,(1991).

[12]. Proc. 10 ${ }^{\text {th }}$ Int. Conf. on Noise in Physical Systems, Budapest, Aug 1989, (Ed. A. Ambrozy), Budapest; Akademiaikiodo. (1990).

[13]. Walker S. 'FFT Studies in Advanced Mechanics', Second Edition, (1996).

[14]. Blahut R E, 'Fast Algorithms for Digital Signal Processing', Addison - Wesley, Reading (1985).

[15] D. Wolf "Noise in Physical Systems", Springer-Verlag, Erlin. Heidelberg, New York. (1978).

[16] E.J.P. May and J.M.K. Hardwood, Proc. Symp on 1/f fluctuations, Tokyo, p 124 (1977).

[17] GS Koushik, CM Van Vliet. Bosman, and H.J. Luo, "Quntum 1/f noise associated with inner valence scattering in non-degenerate semiconductors", Physica Status Solidi, B 154, p 713, (1989).

[18] CM Van Vliet, "A survey of the results and the future prospects on quantum 1/f noise and 1/f noise in general", Solid State Electron., 34 p 1 (1991). 